\title{
Experience-Enabled Enhancement of Adult Visual Cortex Function
}

\author{
Wayne W. Tschetter, ${ }^{1}$ Nazia M. Alam, ${ }^{1}$ Christopher W. Yee, ${ }^{2}$ Mario Gorz, ${ }^{1}$ Robert M. Douglas, ${ }^{3}$ Botir Sagdullaev, ${ }^{2}$ \\ and Glen T. Prusky ${ }^{1}$ \\ Departments of ${ }^{1}$ Physiology and Biophysics and ${ }^{2}$ Ophthalmology, Weill Medical College of Cornell University, Burke Medical Research Institute, White \\ Plains, New York, 10605, and ${ }^{3}$ Department of Ophthalmology and Visual Sciences, University of British Columbia, Vancouver, British Columbia, Canada \\ V5Z 3N9
}

We previously reported in adult mice that visuomotor experience during monocular deprivation (MD) augmented enhancement of visual-cortex-dependent behavior through the non-deprived eye (NDE) during deprivation, and enabled enhanced function to persist after MD. We investigated the physiological substrates of this experience-enabled form of adult cortical plasticity by measuring visual behavior and visually evoked potentials (VEPs) in binocular visual cortex of the same mice before, during, and after MD. MD on its own potentiated VEPs contralateral to the NDE during MD and shifted ocular dominance (OD) in favor of the NDE in both hemispheres. Whereas we expected visuomotor experience during MD to augment these effects, instead enhanced responses contralateral to the NDE, and the OD shift ipsilateral to the NDE were attenuated. However, in the same animals, we measured NMDA receptor-dependent VEP potentiation ipsilateral to the NDE during MD, which persisted after MD. The results indicate that visuomotor experience during adult MD leads to enduring enhancement of behavioral function, not simply by amplifying MD-induced changes in cortical OD, but through an independent process of increasing NDE drive in ipsilateral visual cortex. Because the plasticity is resident in the mature visual cortex and selectively effects gain of visual behavior through experiential means, it may have the therapeutic potential to target and non-invasively treat eye- or visual-field-specific cortical impairment.

\section{Introduction}

Plasticity of visual function in adulthood is thought to be constrained by inherent limitations of the mature visual cortex to undergo experience-dependent synaptic change (Hensch, 2005; Baroncelli et al., 2011b). One of the strategies to overcome this deficit has been to reactivate a developmental form of ocular dominance (OD) plasticity, which is typically expressed as a monocular deprivation (MD)-induced shift in neuronal responses in binocular primary visual cortex (V1b) away from the deprived eye (DE; Wiesel and Hubel, 1963; Hubel and Wiesel, 1970), with accompanying DE amblyopia (Giffin and Mitchell, 1978; Prusky and Douglas, 2003). Indeed, several interventions have shown promise in inducing OD plasticity with developmental characteristics in adult visual cortex (Pizzorusso et al., 2006; Bavelier et al., 2010; Southwell et al., 2010; Baroncelli et al., 2011a) and treating monocular amblyopia (Sale et al., 2007; Baroncelli et al., 2012; Scali et al., 2012).

However, there is growing evidence that the capacity of the adult visual cortex to undergo experience-dependent change has

Received 0ct. 23, 2012; revised Jan. 23, 2013; accepted Feb. 12, 2013.

Author contributions: W.W.T. and G.T.P. designed research; W.W.T., N.M.A., and M.G. performed research; R.M.D. contributed unpublished reagents/analytic tools; W.W.T., C.W.Y., and B.S. analyzed data; W.W.T., B.S., and G.T.P. wrote the paper.

G.T.P. and R.M.D. are principals in a company that manufactures equipment used in this study.

Correspondence should be addressed to Glen Prusky, Burke-Cornell Medical Research Institute, 785 Mamaroneck Avenue, White Plains, NY 10605. E-mail: glp2004@med.cornell.edu.

DOI:10.1523/JNEUROSCI.5229-12.2013

Copyright $\odot 2013$ the authors $\quad 0270-6474 / 13 / 335362-05 \$ 15.00 / 0$ been underestimated and, as such, that reinstating developmental plasticity may not be the only viable strategy to stimulate plasticity of adult visual function. For example, adult OD plasticity has been reported in mice, in the form of an $\mathrm{MD}$-induced $\mathrm{OD}$ shift in V1b ipsilateral to the non-deprived eye (NDE), primarily attributable to potentiation of NDE responses (Sawtell et al., 2003; Frenkel and Bear, 2004; Hofer et al., 2006a,b, 2009; Lehmann and Löwel, 2008; Sato and Stryker, 2008). We investigated the effect of MD in adult mice on visual behavior using optokinetic tracking (OKT; Prusky et al., 2006), a conserved visuomotor function that serves to stabilize retinal imagery through reflexive head and neck movements. Indeed, we found that visual-cortex-dependent OKT thresholds through the NDE became enhanced during MD. However, because enhancement was lost immediately on opening the $\mathrm{DE}$, the result also indicated that simply shifting OD was not sufficient to elicit an enduring change of visual behavior. Therefore, in the same study, we investigated the ability of brief, daily visuomotor experience [combined threshold measurement of spatial frequency (SF) and contrast thresholds for OKT] through the NDE during MD to effect lasting behavioral change. Indeed, we found that the experiential treatment augmented NDE enhancement during deprivation and enabled enhancement to persist after MD, without reducing function through the DE.

Because stimulating gain of visual function is the clinical goal for treating adult visual impairment, we were motivated in the present study to identify physiological substrates in visual cortex that support this novel form of experience-enabled plasticity. We 
also aimed to determine how visual experience interacts with MD-induced adult OD plasticity, because recent evidence has indicated that the mechanisms of adult OD plasticity and experience-enabled enhancement of visual function may be distinct (Greifzu et al., 2011). Thus, in groups of adult mice with MD alone or with visuomotor experience during MD, we combined the measurement of OKT thresholds and visually evoked potentials (VEPs) through each eye in V1b bilaterally before, during, and after MD.

\section{Materials and Methods}

Experimental animals. Young adult male and female C57BL/6 mice from Charles River, in standard housing conditions, were used as subjects. Procedures were approved by the Weill-Cornell Institutional Animal Care and Use Committee.

Measurement of visuomotor behavior. OKT thresholds were quantified as described previously (OptoMotry; CerebralMechanics) (Prusky et al., 2004; Douglas et al., 2005). Briefly, four computer monitors formed a testing arena, a vertical sine-wave grating was projected on the monitors as a virtual cylinder, and mice were placed on a platform at the epicenter. A crosshair superimposed on an overhead video image was used to center the hub of the cylinder at the animal's viewing position and maintain the SF of the grating in real time as the animal moved freely. Thresholds were obtained using a method of limits procedure. For SF thresholds, mice were exposed to moving gratings $(12 \%)$ of maximal contrast, which incremented from 0.03 cycles per degree $\left(\mathrm{c} /{ }^{\circ}\right)$, and decremented from $0.75 \mathrm{c} /{ }^{\circ}$ over multiple short trials, until the highest SF to elicit tracking was identified. Only temporal-to-nasal motion elicits tracking (Douglas et al., 2005), and thus, thresholds through each eye were tested with both eyes open by altering the direction of cylinder rotation. Using similar procedures, contrast thresholds at six SFs $(0.031,0.064,0.092,0.103$, 0.192 , and $0.272 \mathrm{c} /{ }^{\circ}$ ) were also measured, with grating contrast being systematically varied to identify the minimum contrast to evoke tracking.

VEPs. Mice were anesthetized with inhaled isoflurane (induction at $4-5 \%$, maintenance at $1.5-2.5 \%$ evaporated in $1-1.5 \mathrm{~L} / \mathrm{min}_{2}$ ) and secured in a stereotaxic frame. The head was shaved and wiped with $10 \%$ povidone-iodine and $70 \%$ ethanol, a topical anesthetic (bupivacaine; $0.25 \%$ ) was applied before a midline scalp incision was made, and the skin was resected to expose the skull, which was dried with acetone. Holes were drilled in the skull, and platinum electrodes (0.005-inch diameter; impedance, $\sim 400 \mathrm{M} \Omega$ ) were implanted in V1b in each hemisphere $(0.0$ $\mathrm{mm}$ lambda anteroposterior, $\pm 3.00 \mathrm{~mm}$ mediolateral, $-0.45 \mathrm{~mm}$ dorsoventral to pial surface). Silver reference electrodes were positioned on frontal cortex bilaterally, and the electrode array with a head post was adhered to the skull within a cyanoacrylate matrix.

After recovery of at least $24 \mathrm{~h}$, awake mice were placed in a tube with their head exposed, and the head post was secured to a stabilizing arm to fix their gaze tangent to a computer monitor (17-inch Dell CRT \#M768 with gamma correction) at $20 \mathrm{~cm}$. Signals were amplified (DP-311; Warner Instruments) and acquired using a Micro1401 unit (Cambridge Electronic Design) controlled by Spike2 software (Cambridge Electronic Design). Sixty-cycle noise (50-70 Hz notch filter) and direct current offset ( $2 \mathrm{~Hz}$ high-pass filter) were filtered. In addition, high-pass $(0.1 \mathrm{~Hz})$ and low-pass $(100 \mathrm{~Hz})$ filtering was used for signal acquisition. Counterphasing $\left(1 \mathrm{~Hz}\right.$ ) sine-wave gratings (seven SFs from 0.05 to $1.0 \mathrm{c} /{ }^{\circ}$ at maximal contrast) were generated with a MATLAB (MathWorks) script using Psychophysics Toolbox extensions (Brainard, 1997; Pelli, 1997) and projected on the monitor. Each SF was presented randomly three times for $40 \mathrm{~s}$, interleaved with $10 \mathrm{~s}$ of gray, resulting in $120 \mathrm{~s}$ of stimulation at each of the seven SFs. Acquisition of the signal was continuous and averaged at the reversal of each grating cycle ( $1 \mathrm{~s}$ for $1 \mathrm{~Hz}$ stimulation). Responses to $0 \%$ contrast were subtracted from VEPs, and VEP amplitude was quantified as the peak-to-peak response. Grating SF was randomized to preclude stimulus-specific potentiation (Frenkel et al., 2006; Cooke and Bear, 2010) across recording sessions. Gratings at $0.05 \mathrm{c} /{ }^{\circ}$ generated the largest amplitude responses and are thus reported here. Recordings were made before and after MD with stimuli presented independently to the left and right eyes in random order (with the aid of a

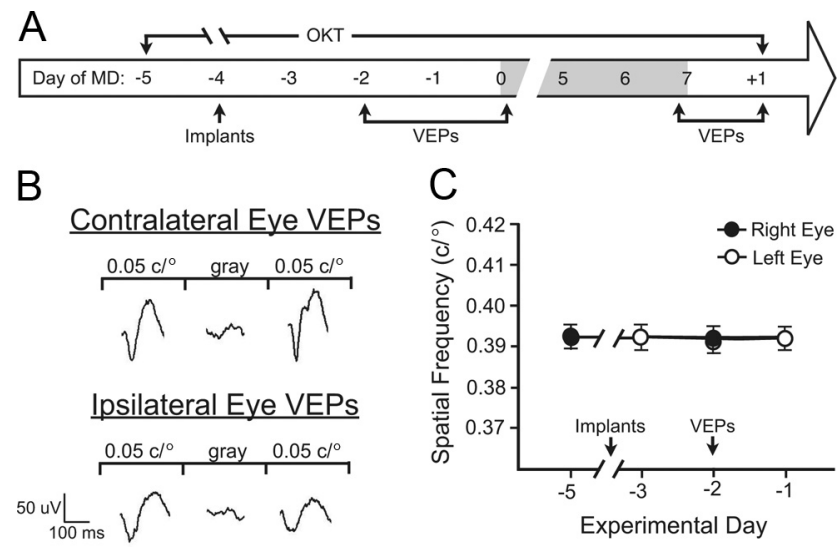

Figure 1. Experimental timeline and methodology. $\boldsymbol{A}, 0 \mathrm{KT}$ measures commenced $5 \mathrm{~d}$ before $(-5)$ MD (shaded region; day 0 is the first $24 \mathrm{~h}$ ). Recording electrodes were implanted $4 \mathrm{~d}$ before $(-4) M D$ (day with no visual testing). VEPs were recorded before (days -2 to -1 ), during (day 0 , within 4 h of MD; day 7 , within 4 h of eye opening), and after (day + 1) MD. B, VEP recordings: averaged VEPs contralateral (top) and ipsilateral to a stimulated eye, before and after presentation of equiluminant gray. Calibration: VEP amplitude ( $\mu \mathrm{V})$, vertical; time (ms), horizontal. C, OKT baseline: thresholds through both eyes (right eye, black circles; left eye, white circles) were unchanged by electrode implantation (-4) and VEP recording (day -2 ). Error bars are SEMs in this and other OKT data panels but are often smaller than symbols.

monocular occluder) and during MD through the NDE. An OD index was computed from separate eye responses (contralateral - ipsilateral/ contralateral plus ipsilateral; Sato and Stryker, 2008).

$M D$. Mice were anesthetized (as above), the eyelids were sewn (5.0 Ethilon) closed with pillow stitches below the eyelid margin, and a topical anesthetic $(0.5 \%$ proparacine hydrochloride) was applied to the wound. Animals were re-anesthetized, and the stitches were removed to terminate deprivation. Eyes were monitored regularly for clarity, and only animals with clear optics were included.

NMDA receptor blockade. The NMDA receptor antagonist 3-(2carboxypiperazin-4-yl)propyl-1-phosphonic acid (CPP; Tocris Bioscience) was dissolved in water $(2 \mathrm{mg} / \mathrm{ml})$ and injected intraperitoneally (10 $\mathrm{mg} / \mathrm{kg}$ ). The first injection was made $24 \mathrm{~h}$ before MD surgery, and on subsequent days, injections were made $2 \mathrm{~h}$ before visual thresholds were measured (Villarreal et al., 2002).

\section{Results}

\section{Experimental design and methodology}

Figure $1 A$ illustrates the experimental timeline and measurements used to assess the impact of visuomotor experience [measurements of OKT thresholds for SF and contrast sensitivity $(\mathrm{CS})(\sim 10 \mathrm{~min})$ amid otherwise normal visual experience] during adult MD. OKT thresholds were assessed from $5 \mathrm{~d}$ before $(-5)$ to $1 \mathrm{~d}$ after $(+1) 7 \mathrm{~d}$ of MD, and VEPs were recorded in the same animals on the 2 days preceding MD $(-2,-1)$, on the first $(0)$ and last day (7) of MD, and on the day after $\mathrm{MD}(+1)$.

Before MD $(-2)$, we established that stimulation of the eye contralateral to a recording electrode produced large $(\sim 90 \mu \mathrm{V})$ and consistent VEPs (Fig. 1B, top traces) and ipsilateral stimulation produced smaller amplitude $(\sim 60 \mu \mathrm{V})$ VEPs (Fig. $1 B$, bottom traces). Equiluminant gray did not generate VEPs through either eye, and electrode implantation $(-4)$ and VEP measurement (-2) did not affect OKT (Fig. 1C).

\section{Experience-enabled enhancement of visual function}

In mice with chronically implanted electrodes, we replicated our previous finding (Prusky et al., 2006) that MD transiently enhances OKT SF thresholds during MD (Fig. 2A, filled triangles). We also confirmed that visuomotor experience during MD aug- 

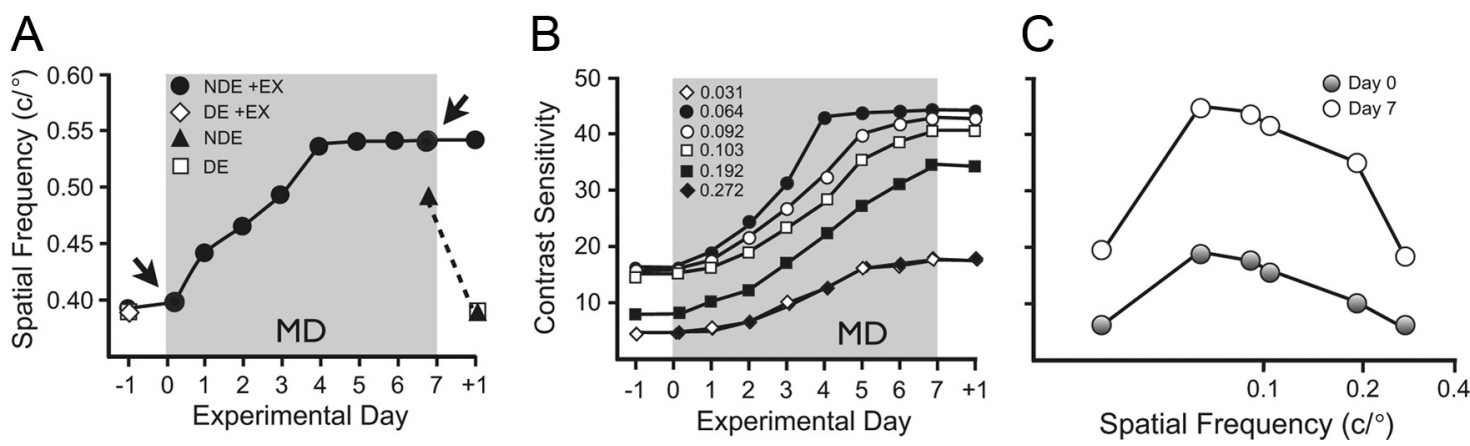

Figure 2. Experience-enabled enhancement of visual behavior. $A, M D$ had no effect on $D E$ (white squares) or NDE (black triangle; -1 vs +1$) 0 \mathrm{KT} \mathrm{SF}$ thresholds $\left(\sim 0.39 \mathrm{c} /{ }^{\circ}\right)$. MD alone led to a temporary enhancement $\left(\sim 0.49 \mathrm{c} /{ }^{\circ}\right.$; black triangle) of NDE function during $M D$ (measured just before eye opening on day 7 ). Experience ( + EX) during MD enhanced function through the NDE (black circles), which reached a maximum $\left(\sim 0.53 \mathrm{c} /{ }^{\circ}\right)$ by $4 \mathrm{~d}$. Thresholds through the $D E$ (white diamond) were not affected by the same treatment. Arrows denote experimental days highlighted in $\boldsymbol{C}$. $\boldsymbol{B}$, CS [screen luminance (maximum - minimum)/(maximum + minimum) plotted as the reciprocal of the contrast threshold] at all SFs was enhanced over the course of MD. The rate of enhancement varied with SF, but all reached maximum by $7 \mathrm{~d}$. C, CS data from $B$ plotted as a function of SF on the first and last day of MD shows general enhancement of CS between day 0 (gray circles) and day 7 (white circles).

mented enhancement (Fig. 2A, filled circles; maximal enhancement by $4 \mathrm{~d}$ ) and enabled enhancement to persist after MD. $\mathrm{MD}$ on its own, or with visuomotor experience, did not affect function through the DE (white symbols). CS was also enhanced in mice with visuomotor experience during $\mathrm{MD}$ (Fig. 2B); the rate of enhancement varied with SF, but maximal enhancement was attained at all SFs by day 7 (Fig. $2 B, C$ ).

\section{Experience-enabled enhancement of visual cortical function during MD} We evaluated the effect on cortical VEPs of MD on its own (Fig. 3A) and with daily experience (Fig. $3 B$ ), by normalizing VEP amplitude on day 7 to day 0. MD alone resulted in a small increase in VEP amplitude contralateral to the $\operatorname{NDE}(p=0.0469, n=12)$ but no change in ipsilateral V1b $(p=0.1795, n=13$; Fig. $3 A)$. Because visuomotor experience enhanced visual function during $\mathrm{MD}$ (Fig. $2 A$ ), we expected that MD-induced enhancement of VEPs contralateral to the NDE would be augmented. Instead, we found no enhancement contralateral to the $\operatorname{NDE}(p=0.3581, n=12)$ but a large increase in VEPs in ipsilateral V1b $(p=0.0013, n=12$; Fig. $3 B$ ). This potentiation was blocked by CPP (gray bar; $p=0.4515$, $n=5$ ), as was the accompanying enhancement of visual behavior (Fig. 3C).

\section{Visuomotor experience blocks the MD-induced OD shift ipsilateral to the NDE}

Previous studies have reported that MD in adult mice shifts OD in V1b ipsilateral to the NDE by enhancing NDE responses (Sawtell et al., 2003; Frenkel and Bear, 2004; Hofer et al., 2006a, 2009; Lehmann and Löwel, 2008; Sato and Stryker, 2008). This, in conjunction with our finding that visuomotor experience during MD enhances visual function through the NDE (Fig. 2A) and NDE VEPs in ipsilateral V1b (Fig. 3B), led us to hypothesize that visuomotor experience during MD would augment the OD shift. We thus compared OD before $(-1)$ and after $(+1)$ MD in groups with and without visuomotor experience during MD. OD was shifted in both hemispheres with MD alone (Fig. 4A): contralateral to the NDE, the OD index increased (Fig. $4 A$, black circles;
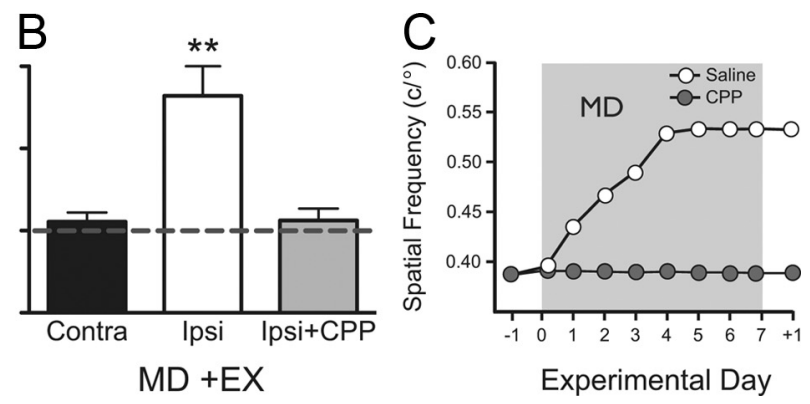

Figure 3. MD-induced changes in cortical VEPs. $\boldsymbol{A}$, In mice with MD alone (MD), NDE VEPs were significantly potentiated over the course of MD in V1b contralateral to the NDE [black bar; plotted as change relative to baseline (dashed line) by normalizing treatment (gray circles) also blocked (relative to saline-injected controls; white circles) the experience-enabled enhancement of OKT SF thresholds in the same animals.

0.32 before $\mathrm{MD}$ to 0.51 after $\mathrm{MD}, p=0.0005, n=9)$ and decreased in the ipsilateral hemisphere (Fig. $4 A$, white circles; 0.31 before MD to 0.21 after $\mathrm{MD}, p=0.0326, n=7)$. However, in animals with daily experience during MD, OD was not augmented (Fig. 4B): in V1b contralateral to the NDE, a significant OD shift was present (black circles; 0.31 before MD to 0.51 after $\mathrm{MD}, p=0.0476, n=7$ ), which was similar to the MD-alone condition. More surprisingly, we measured no OD shift in the hemisphere ipsilateral to the NDE (Fig. $4 B$, white circles; 0.28 before $\mathrm{MD}$ and 0.24 after $\mathrm{MD}, p=0.6460, n=8$ ).

An analysis of VEP response magnitudes through each eye in the MD-only condition (Fig. $4 C$ ) revealed that the OD shift in the hemisphere contralateral to the NDE was attributable to an increase in responses of the NDE $(92.0 \pm 11.0 \mu \mathrm{V}$ before MD to $156.2 \pm 27.4 \mu \mathrm{V}$ after $\mathrm{MD}, p=0.0442, n=9)$. Conversely, in the ipsilateral hemisphere, OD shifted as a result of a nonsignificant increase in NDE responses $(46.2 \pm 8.6 \mu \mathrm{V}$ before MD to $57.4 \pm$ $7.0 \mu \mathrm{V}$ after $\mathrm{MD}, p=0.0745, n=7)$ and a nonsignificant decrease in DE responses (Fig. $4 C ; 93.5 \pm 19.9 \mu \mathrm{V}$ before MD to $87.7 \pm 7.8 \mu \mathrm{V}$ after $\mathrm{MD}, p=0.7235, n=7)$. However, responses in animals with visuomotor experience during MD (Fig. 4D) were significantly potentiated in both hemispheres (Fig. $4 D$, left hemisphere: ipsilateral, $34.2 \pm 3.9$ before MD to $44.7 \pm 9.4 \mu \mathrm{V}$ after MD, $p=0.3689, n=6$; contralateral, $81.2 \pm 17.7 \mu \mathrm{V}$ before $\mathrm{MD}$ to $151.8 \pm 20.8 \mu \mathrm{V}$ after $\mathrm{MD}, p=0.0111, n=6$; right 

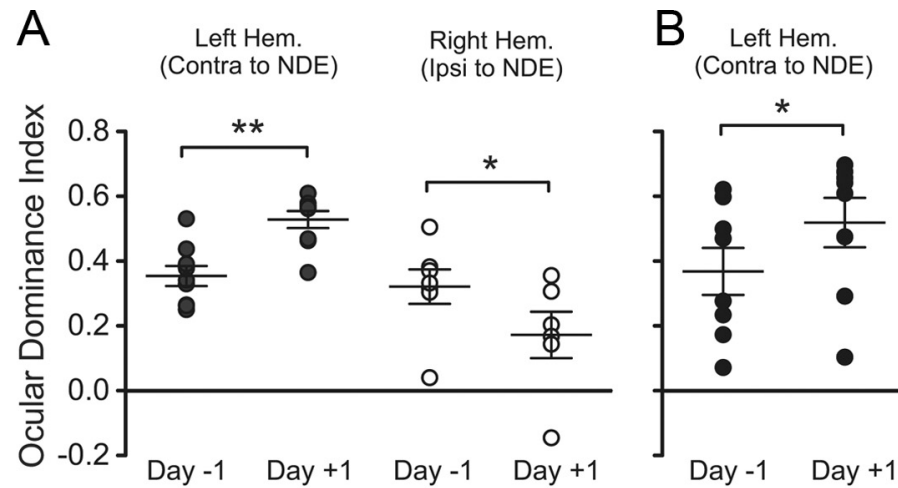

Right Hem (Contra to NDE) (Ipsi to NDE)
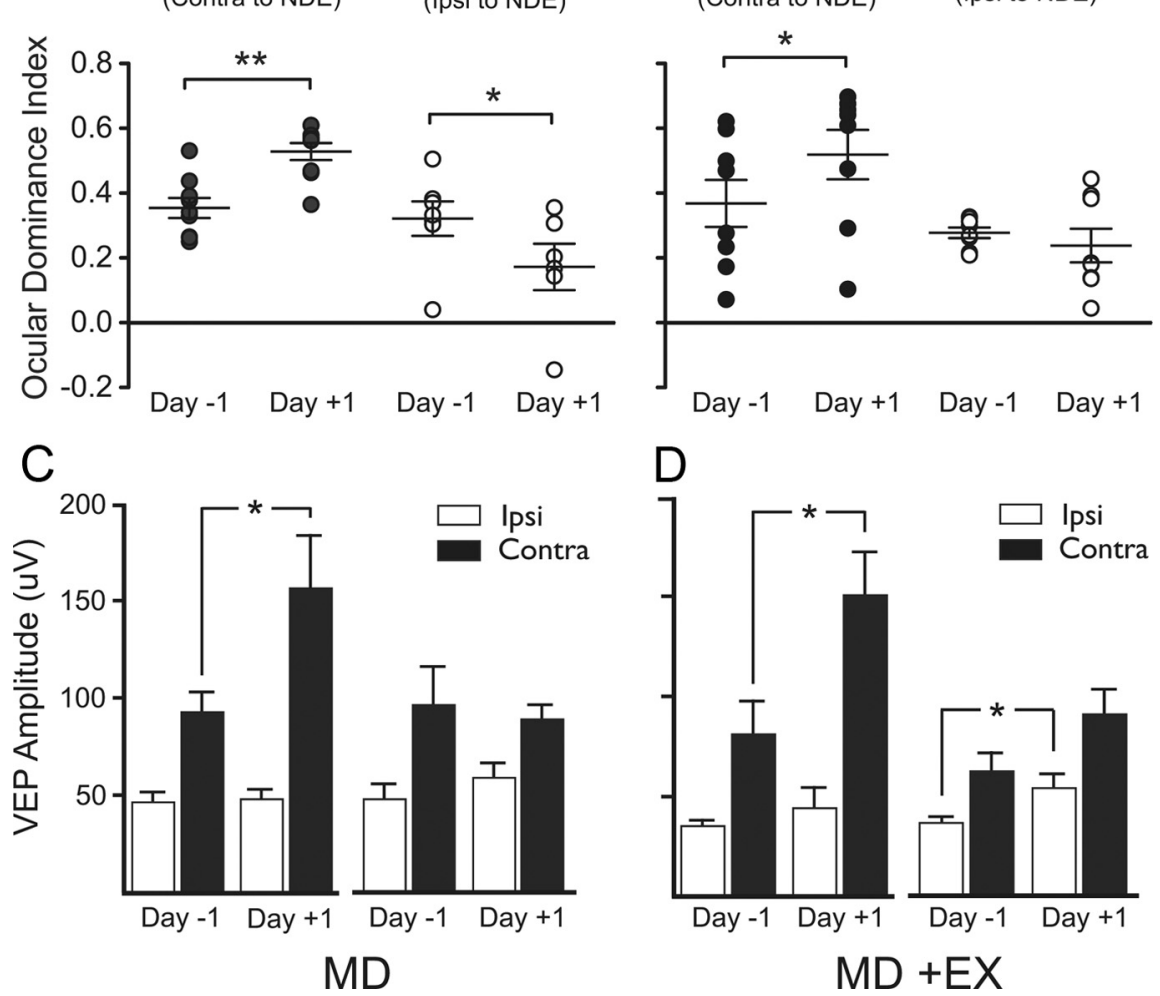

D

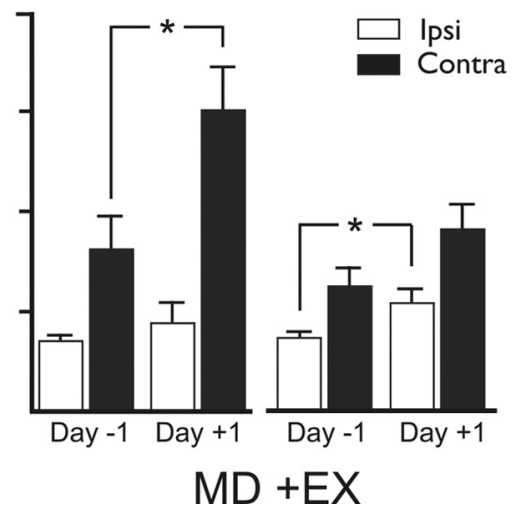

Figure 4. Experience-dependent change after MD. $A, 0 D$ in both hemispheres was shifted by MD alone (left panels). Data from individual animals are plotted; long line is group average; short lines are $\pm S E M s ;{ }^{*} p=0.0326,{ }^{* *} p=0.0005 . B, A$ significant increase in the OD index contralateral to the NDE was maintained in mice with experience during MD (MD + EX; right panels), but OD was not changed in the ipsilateral hemisphere; ${ }^{*} p=0.0476$. C, D, VEP amplitudes used to calculate OD in $\boldsymbol{A}$. $\boldsymbol{C}$, An increase in NDE responses in the left hemisphere contralateral to the NDE (black bars) was the only significant change; ${ }^{*} p=0.0442 . D, A$ significant increase in NDE responses in the left hemisphere contralateral to the NDE was accompanied by a significant increase in the right hemisphere ipsilateral to the NDE in mice with experience during MD; ${ }^{*} p=0.0111$ (contra), ${ }^{*} p=0.0305$ (ipsi).

hemisphere: ipsilateral, $35.8 \pm 4.4 \mu \mathrm{V}$ before MD to $53.4 \pm 7.5$ $\mu \mathrm{V}$ after $\mathrm{MD}, p=0.0305, n=6$; contralateral, $61.7 \pm 10.1 \mu \mathrm{V}$ before $\mathrm{MD}$ to $90.6 \pm 13.1 \mu \mathrm{V}$ after $\mathrm{MD}, p=0.0768, n=6)$.

\section{Discussion}

We tested the hypothesis that visuomotor experience during adult MD, which leads to enhancement of visual behavior, was the result of augmenting a cortical OD shift in favor of the NDE. We found instead that OD plasticity was attenuated by experience during MD. However, at the same time, we uncovered other physiological changes in V1b that accompany experienceenabled enhancement of visual function, in the form of a reduced influence of the NDE in contralateral V1b, and increased drive of the NDE in ipsilateral V1b. As such, these results expand the evidence that MD- and experience-enabled enhancement of adult visual function depends on visual cortex (Prusky et al., 2006). They also show that the physiological changes that support the plasticity are distinct from those underlying adult MD-induced OD plasticity.

The relationship between experience-dependent changes in visual cortex physiology and visual behavior is complex. Murphy and Mitchell $(1986,1987)$ have reported that reverse occlusion after developmental MD can result in normal OD but leave both eyes amblyopic, showing that the state of OD does not necessarily reflect the state of visual acuity. Our results add to the evidence of a discord between OD and visual behavior by showing that shifted OD is positively correlated with NDE visual enhancement during MD on its own, but not when enhancement is augmented and consolidated into an enduring form with visual experience. However, the lack of an OD shift in V1b ipsilateral to the NDE in animals with enabling experience did not signal the absence of physiological change after MD. In fact, the NDE evoked significantly larger VEPs in the ipsilateral hemisphere than would be expected for an OD shift to occur (Fig. 4D), but the contralateral DE also evoked larger VEPs. Mrsic-Flogel et al. (2007) have reported that $\mathrm{DE}$ responses in $\mathrm{V} 1$ are strengthened after MD, depending on the amount of open-eye input a cell receives, indicating the presence of compensatory processes in cortical circuitry that alters synaptic transmission or intrinsic excitability (Desai et al., 2002; Maffei et al., 2004). Thus, one possibility is that a homeostatic mechanism, such as synaptic scaling, compensated for potentiation of NDE ipsilateral responses by equalizing the responses of the two eyes (Desai, 2003; Turrigiano and Nelson, 2004), causing DE potentiation. This effect was not detected in the MD-alone condition, in which there was only a small potentiation of NDE-driven VEPs. That a significant OD shift occurred in V1b contralateral to the NDE, both without and with experience during MD, suggests that eyelid suture on its own is sufficient to induce an OD shift in the hemisphere but occurs independently of enduring changes in behavior (Fig. 4A). As such, visuomotor experience during MD appears to induce an "absolute" change in the responsivity of each eye in V1 ipsilateral to the NDE, thereby mitigating an OD shift in that hemisphere.

Together, the results indicate that there are separable processes induced by MD and visuomotor experience during MD in adult V1, likely with different mechanisms of control. Our paradigm provides a framework to dissociate the cellular mechanisms of these processes in future work, with the goal of independently manipulating them for therapeutic advantage. In addition, the ability to stimulate gain-of-visual function in adulthood without the use of invasive procedures provides an alternative or complement to recapitulating developmental OD plasticity as a model to enable recovery of function. The first steps toward this goal have already been taken in adult humans by showing that long-term plasticity can be elicited with NDE training after MD (Shibata et al., 2012) and that interactive visuomotor experience through an amblyopic eye during monocular patching can facilitate recovery of function (Li et al., 2011).

\section{References}

Baroncelli L, Braschi C, Spolidoro M, Begenisic T, Maffei L, Sale A (2011a) Brain plasticity and disease: a matter of inhibition. Neural Plast 2011: 286073. CrossRef Medline

Baroncelli L, Maffei L, Sale A (2011b) New perspectives in amblyopia therapy on adults: a critical role for the excitatory/inhibitory balance. Front Cell Neurosci 5:25. CrossRef Medline

Baroncelli L, Bonaccorsi J, Milanese M, Bonifacino T, Giribaldi F, Manno I, Cenni MC, Berardi N, Bonanno G, Maffei L, Sale A (2012) Enriched 
experience and recovery from amblyopia in adult rats: impact of motor, social and sensory components. Neuropharmacology 62:2388-2397. CrossRef Medline

Bavelier D, Levi DM, Li RW, Dan Y, Hensch TK (2010) Removing brakes on adult brain plasticity: from molecular to behavioral interventions. J Neurosci 30:14964-14971. CrossRef Medline

Brainard DH (1997) The psychophysics toolbox. Spat Vis 10:433-436. CrossRef Medline

Cooke SF, Bear MF (2010) Visual experience induces long-term potentiation in the primary visual cortex. J Neurosci 30:16304-16313. CrossRef Medline

Desai NS (2003) Homeostatic plasticity in the CNS: synaptic and intrinsic forms. J Physiol Paris 97:391-402. CrossRef Medline

Desai NS, Cudmore RH, Nelson SB, Turrigiano GG (2002) Critical periods for experience-dependent synaptic scaling in visual cortex. Nat Neurosci 5:783-789. CrossRef Medline

Douglas RM, Alam NM, Silver BD, McGill TJ, Tschetter WW, Prusky GT (2005) Independent visual threshold measurements in the two eyes of freely moving rats and mice using a virtual-reality optokinetic system. Vis Neurosci 22:677-684. CrossRef Medline

Frenkel MY, Bear MF (2004) How monocular deprivation shifts ocular dominance in visual cortex of young mice. Neuron 44:917-923. CrossRef Medline

Frenkel MY, Sawtell NB, Diogo AC, Yoon B, Neve RL, Bear MF (2006) Instructive effect of visual experience in mouse visual cortex. Neuron 51:339-349. CrossRef Medline

Giffin F, Mitchell DE (1978) The rate of recovery of vision after early monocular deprivation in kittens. J Physiol 274:511-537. Medline

Greifzu F, Schmidt S, Schmidt KF, Kreikemeier K, Witte OW, Lowel S (2011) Global impairment and therapeutic restoration of visual plasticity mechanisms after a localized cortical stroke. Proc Natl Acad Sci U S A 37: 15450-15455. CrossRef Medline

Hensch TK (2005) Critical period plasticity in local cortical circuits. Nat Rev Neurosci 6:877-888. CrossRef Medline

Hofer SB, Mrsic-Flogel TD, Bonhoeffer T, Hübener M (2006a) Prior experience enhances plasticity in adult visual cortex. Nat Neurosci 9:127-132. CrossRef Medline

Hofer SB, Mrsic-Flogel TD, Bonhoeffer T, Hübener M (2006b) Lifelong learning: ocular dominance plasticity in mouse visual cortex. Curr Opin Neurobiol 16:451-459. CrossRef Medline

Hofer SB, Mrsic-Flogel TD, Bonhoeffer T, Hübener M (2009) Experience leaves a lasting structural trace in cortical circuits. Nature 457:313-317. CrossRef Medline

Hubel DH, Wiesel TN (1970) The period of susceptibility to the physiological effects of unilateral eye closure in kittens. J Physiol 206:419-436. Medline

Lehmann K, Löwel S (2008) Age-dependent ocular dominance plasticity in adult mice. PLoS One 3:e3120. CrossRef Medline

Li RW, Ngo C, Nguyen J, Levi DM (2011) Video-game play induces plasticity in the visual system of adults with amblyopia. PLoS Biol 9:e1001135. CrossRef Medline

Maffei A, Nelson SB, Turrigiano GG (2004) Selective reconfiguration of layer 4 visual cortical circuitry by visual deprivation. Nat Neurosci 12 : 1353-1359. CrossRef Medline
Mrsic-Flogel TD, Hofer SB, Ohki K, Reid RC, Bonhoeffer T, Hübener M (2007) Homeostatic regulation of eye-specific responses in visual cortex during ocular dominance plasticity. Neuron 54:961-972. CrossRef Medline

Murphy KM, Mitchell DE (1986) Bilateral amblyopia after a short period of reverse occlusion in kittens. Nature 323:536-538. CrossRef Medline

Murphy KM, Mitchell DE (1987) Reduced visual acuity in both eyes of monocularly deprived kittens following a short or long period of reverse occlusion. J Neurosci 7:1526-1536. Medline

Pelli DG (1997) The VideoToolbox software for visual psychophysics: transforming numbers into movies. Spat Vis 10:437-442. CrossRef Medline

Pizzorusso T, Medini P, Landi S, Baldini S, Berardi N, Maffei L (2006) Structural and functional recovery from early monocular deprivation in adult rats. Proc Natl Acad Sci U S A 103:8517-8522. CrossRef Medline

Prusky GT, Douglas RM (2003) Developmental plasticity of mouse visual acuity. Eur J Neurosci 17:167-173. CrossRef Medline

Prusky GT, Alam NM, Beekman S, Douglas RM (2004) Rapid quantification of adult and developing mouse spatial vision using a virtual optomotor system. Invest Ophthalmol Vis Sci 45:4611-4616. CrossRef Medline

Prusky GT, Alam NM, Douglas RM (2006) Enhancement of vision by monocular deprivation in adult mice. J Neurosci 26:11554-11561. CrossRef Medline

Prusky GT, Silver BD, Tschetter WW, Alam NM, Douglas RM (2008) Experience-dependent plasticity from eye opening enables lasting, visual cortex-dependent, enhancement of motion vision. J Neurosci 28:9817-9827. CrossRef Medline

Sale A, Maya Vetencourt JF, Medini P, Cenni MC, Baroncelli L, De Pasquale R, Maffei L (2007) Environmental enrichment in adulthood promotes amblyopia recovery through a reduction of intracortical inhibition. Nat Neurosci 10:679-681. CrossRef Medline

Sato M, Stryker MP (2008) Distinctive features of adult ocular dominance plasticity. J Neurosci 28:10278-10286. CrossRef Medline

Sawtell NB, Frenkel MY, Philpot BD, Nakazawa K, Tonegawa S, Bear MF (2003) NMDA receptor-dependent ocular dominance plasticity in adult visual cortex. Neuron 38:977-985. CrossRef Medline

Scali M, Baroncelli L, Cenni MC, Sale A, Maffei L (2012) A rich environmental experience reactivates visual cortex plasticity in aged rats. Exp Gerontol 47:337-341. CrossRef Medline

Shibata K, Kawato M, Watanabe T, Sasaki Y (2012) Monocular deprivation boosts long-term visual plasticity. Curr Biol 22:R291-R292. CrossRef Medline

Southwell DG, Froemke RC, Alvarez-Buylla A, Stryker MP, Gandhi SP (2010) Cortical plasticity induced by inhibitory neuron transplantation. Science 327:1145-1148. CrossRef Medline

Turrigiano GG, Nelson SB (2004) Homeostatic plasticity in the developing nervous system. Nat Rev Neurosci 5:97-107. CrossRef Medline

Villarreal DM, Do V, Haddad E, Derrick BE (2002) NMDA receptor antagonists sustain LTP and spatial memory: active processes mediate LTP decay. Nat Neurosci 5:48-52. CrossRef Medline

Wiesel TN, Hubel DH (1963) Single-cell responses in striate cortex of kittens deprived of vision in one eye. J Neurophysiol 26:1003-1017. Medline 